\title{
Falando de Pronomes $^{1}$
}

Mirta GROPPI

Universidade de São Paulo

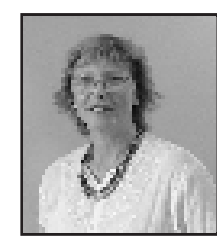

Doutora em Letras pela Universidade de São Paulo - USP.

Instituiç̃o à qual está vinculada como docente: Universidade de São Paulo - USP.

Principais linhas de pesquisa:

- Língua espanhola: descrição, funcionamento e processos interculturais.

- Estudos contrastivos espanhol-português.

Principais publicações:

GROPPI, M. Observando las duplicaciones. In: XIII Congresso da Associação de Lingüística e Filologia da América Latina - ALFAL, 2002, San José - Costa Rica. Anais do XIII Congresso da Associação de Lingüistica e Filologia da América Latina - ALFAL, 2002.

GROPPI, M. Opcionalidad de la duplicación de clíticos en español. In: Hispanismo 2000 ed. Brasília : Ministerio de Educación, Cultura y Deporte - Embajada de España en Brasil, 2001, v. 1 , p. $230-239$.

GROPPI, M. Pronombres clíticos en el español de Montevideo. Pragmalingüística. Cádiz Espanha, v. 2, p. 153-172, 1998.

GROPPI, M.; CAVIGLIA, S.; MALCUORI, M. Estructuras tópico-comentario en español. In: Congresso de ALFAL, 1991, Campinas. Atas do IX Congresso de ALFAL. Campinas: Editora da Unicamp, 1993. p. 267-286.

Signum: Estud. Ling., Londrina, n. 9/1, p. 95-110, jun. 2006 
Resumo: $\mathrm{O}$ artigo apresenta os pronomes pessoais do espanhol em algumas de suas peculiaridades, depois de lembrar qual a característica fundamental das palavras que são chamadas de pronomes.

Palavras-chave: Pronomes, deícticos, gramática do espanhol, sintaxis, semântica

Abstract: The aim of this article is to discuss the main characteristic of pronouns and, after that, to present the Spanish personal pronouns and some of their peculiarities.

Key-words: Pronouns, deictics, Spanish grammar, syntax, semantics

Resumen: El artículo pretende lograr una presentación de algunas particularidades de los pronombres personales del español, recordando antes la característica fundamental de esas palabras que llamamos pronombres.

Palabras-clave: Pronombres, deícticos, gramática del español, sintaxis, semántica

\footnotetext{
1 Este trabalho expõe parte do conteúdo do curso Sistemas pronominales: Portugués y Español, ministrado na Universidade Estadual de Londrina, de 26/07/2005 a 30/07/2005, dentro das tarefas do PQI (Programa de Qualificação Institucional) da CAPES, assinado entre a USP e a UEL. Participo do PQI como orientadora da doutoranda Valdirene Zorzo Veloso, professora da UEL e aluna do Programa de Pós-Graduação da Área de Língua Espanhola e Literaturas Espanhola e Hispano-Americana da Faculdade de Filosofia, Letras e Ciências Humanas, USP.
} 


\section{Introdução}

O tema dos pronomes é assunto reiterado em bibliografia referente à descrição de línguas para estrangeiros, no entanto parece nunca esgotado. Quando a língua descrita é o espanhol e a língua dos destinatários do trabalho é o português usado no Brasil, então o tema parece ter sempre razões para novas abordagens. É que a gramática de cada uma das línguas oferece, nesse ponto, diferenças que merecem sempre a tentativa de esclarecimentos.

Aqui vamos, mais uma vez, tratar do assunto.

Em 1, vamos lembrar das características classe de palavras que chamamos pronomes. Em 2, serão apresentadas as formas dos pronomes pessoais do espanhol. Em 3, vamos considerar pontos importantes da gramática dos pronomes.

1. Embora o termo pronome leve à interpretação de que com essa palavra queremos nos referir a um elemento que está no lugar do nome, sabido é que devemos ter o cuidado de interpretar esse estar por da maneira adequada. Vamos ver algum exemplo:

1. O Luiz está no Rio. Ele viajou ontem.

2. Eu não vou viajar hoje. A Mirta vai sair para o Rio amanhã.

Se considerarmos as orações que aparecem acima em 1., podemos ver que o pronome Ele parece corresponder àquela idéia de que é pronome a palavra que está no lugar do nome, no caso, no lugar do sintagma nominal O Luir. Isto é, interpretamos a sentença Ele viajou ontem como uma sentença que 
fala do sujeito da sentença anterior, O Luiz. Podemos dizer que $O$ Luizé o antecedente do pronome Ele ou que o pronome Ele e o sintagma OLuiz têm o mesmo referente, istoé, apontam para o mesmo indivíduo.

No caso das orações em 2. já não interpretamos que o pronome Eu e o sintagma nominal $A$ Mirta possuam o mesmo referente. Isto é, no caso de pronomes de primeira e segunda pessoa parece não ser apropriada a definição de que o pronome é uma palavra que está no lugar do nome.

$\mathrm{O}$ que os pronomes de primeira, segunda e terceira pessoa possuem em comum é a maneira de apontar para as pessoas do ato da comunicação, as pessoas do discurso:

1a. pessoa: quem fala

2a. pessoa: o ouvinte

3a. pessoa: aquela que não é nem o falante nem o ouvinte naquele ato de comunicação.

Essa possibilidade de apontar para indivíduos ou objetos que participam de uma situação de comunicação é a característica de uma classe de elementos lingüísticos que são, por essa qualidade, chamados de deícticos. Um aquí, um lá são deícticos que apontam para lugares relacionados com as pessoas participantes $\mathrm{da}$ comunicação (as pessoas do discurso). Mas também um hoje, um amanhã adquirem valor a partir do momento em que acontece o ato comunicativo. Hoje não é sempre segunda feira, nem o 7 de setembro de 2006, mas poderá ser um ou outro se pronunciado numa segunda feira ou no 7 de setembro de 2006.

Os indivíduos que participam de um ato de fala mudam segundo seja a situação comunicativa, portanto, uma forma como $e u$ tem como significado o apontar para a pessoa que 
esteja falando na situação comunicativa do caso. Podemos confrontar essa maneira de significar dos pronomes (e dos elementos deícticos em geral) com a maneira de significar dos substantivos comuns para perceber com clareza a grande diferença semântica. Se alguém pronuncia a sentença:

\section{Vou comprar uma mesa para a sala}

o ouvinte interpreta a palavra mesa da mesma maneira, seja João como seja Maria quem tenha falado; tenha sido pronunciada no jardim ou na cozinha; isto é, a palavra é interpretada de forma independente da situação de comunicação em que foi dita, independente dos elementos integrantes da situação: falante, ouvinte, objetos presente, lugar, momento.

Os deícticos (e, portanto, os pronomes) por sua vez, pelo fato de apontarem para elementos que constituem a situação de comunicação (falante, ouvinte, objetos presente, lugar, momento), têm seu valor semântico ligado àqueles elementos. E essa é a característica fundamental da classe de palavras que chamamos de pronomes.

Quando a produção é escrita, quem escreve vai criar os elementos que podem ser apontados pelos pronomes: vai introduzir no texto personagens, objetos, lugares, momentos. Os pronomes vão apontar para elementos que sejam apresentados no texto antes do pronome ou depois dele. Quando o elemento apareceu antes no texto, chamamos de anáfora essa forma de apontar, ou vai apontar um elemento que aparecerá depois, e vamos falar em catáfora (que é menos freqüente). 
4. Muchos años después, frente al pelotón de fusilamiento, el coronel Aureliano Buendía había de recordar aquella tarde remota en que su padre lo llevó a conocer el bielo ${ }^{2}$.

5. La tarde caía y ella regresaba lentamente. La tarde caía y ella regresaba lentamente. Ana trabajaba en exceso y estaba agotada.

Em 4., el coronel Aureliano Buendía é o SN que constitui o antecedente do pronome lo que aponta para ese SN anaforicamente.

Em 5., por outro lado, temos uma catáfora: o pronome (ella) aponta para um SN (Ana) que vai aparecer depois no texto.

Outras vezes o pronome aponta fora do texto, como na canção que segue. Geralmente é chamada de deixis essa maneira de mostrar por quem diferencia deixis de anáfora e catáfora:

6. Si yo pudiera unirme

a un vuelo de palomas

y atrevasando lomas

dejar mi pueblo atrás, Os juro por lo que fui que me iria de aquí... ${ }^{3}$

${ }^{2}$ GARCÍA MÁRQUEZ, Gabriel. Cien años de soledad. Buenos Aires. Sudamericana. 1970.

${ }^{3}$ SERRAT, João Manuel. Pueblo blanco. 
2. As formas dos pronomes pessoais do espanhol aparecem no quadro a seguir. Vão ser mencionadas algumas diferenças que correspondem a variações diatópicas, isto é, aquelas variações que aparecem em diferentes pontos do espaço geográfico em que o espanhol é usado. Assim, por exemplo, as formas da segunda pessoa do plural (vosotros, os) não são usadas nos países americanos.

Temos que ler o quadro desta maneira: em sentido vertical, em colunas, aparecem as formas de cada uma das pessoas do discurso; em sentido horizontal, nas diferentes colunas, aparecem as formas que correspondem às diferentes funções na oração, tal como indicado na primeira linha.

Nesse quadro ${ }^{4}$ foram diferenciadas formas que contêm acento (tônicas) e formas sem acento (átonas). As formas que aparecem na coluna da função de sujeito e as formas que aparecem na coluna da função de objeto de preposição, são formas tônicas. As formas que aparecem nas colunas das funções de objeto direto (OD) e objeto indireto (OI) e que estão salientadas com uso de negrito são formas átonas.

${ }^{4}$ ALARCOS (1994). 


\begin{tabular}{|c|c|c|c|c|c|}
\hline & & SUJEITO & OD & OI & $\begin{array}{l}\text { com } \\
\text { preposição }\end{array}$ \\
\hline núm & pessoa & & & & \\
\hline sing. & $1^{a}$ & & me & me & mí, conmigo \\
\hline & $2^{a}$ & tú & te & te & ti, contigo \\
\hline & $3^{a}$ & él, ella & lo, la & le & él, ella \\
\hline refl. & & & se & se & sí, consigo \\
\hline pl. & $1^{\text {a }}$ & nosotros & nos & nos & nosotros \\
\hline & $2^{a}$ & vosotros & os & os & vosotros \\
\hline & $3^{a}$ & ellos, ellas & los, las & les & ellos, ellas \\
\hline refl. & & & se & se & sí, consigo \\
\hline
\end{tabular}

É importante entender a diferença entre essas formas porque o emprego na sentença está muito relacionada a essas características diferentes.

Não vamos tratar da variação que tem a ver com os fenômenos de leísmo, laísmo e loísmo porque neste trabalho o propósito é tratar da gramática padrão. No entanto, lembremos que esses fenômenos referem ao uso dos pronomes átonos de terceira pessoa em funções diferentes das funções em que são usadas na língua padrão. Assim, as formas que aparecem no quadro como formas correspondentes à função de objeto indireto (OI) são, em certos dialetos, usadas para a função de objeto direto (OD), o que é chamado de leísmo. Porém, é necessário dizer que a norma acadêmica tem por padrão o emprego da forma le para o objeto direto quando tem o traço [humano], de tal forma que podemos, em correspondência, dirigir estas palavras ao diretor da firma onde trabalhamos: 
7. Le saludo atentamente

mas também, dependendo de qual seja o nosso dialeto, poderemos usar:

8. Lo saludo atentamente

3. Vamos voltar para aquele quadro das formas dos pronomes pessoais e as diferenças entre formas tônicas e átonas.

As formas tônicas podem preencher sozinhas o espaço que um sintagma nominal ( $\mathrm{SN}$ ) poderia ocupar na sentença. Assim, onde podemos ter um sujeito podemos ter também, em espanhol, um pronome pessoal tônico, daquela coluna que temos marcado como a coluna das formas sujeito

9.

a.La tarde caía y ella regresaba lentamente.

b. La tarde caía y Ana regresaba lentamente.

Esses pronomes tônicos do espanhol são considerados enfáticos ${ }^{5}$, porque só são usados quando o falante quer salientar, de alguma maneira esse sujeito: ou porque quer estabelecer uma oposição (v. exemplo 10) a respeito de um outro sujeito, ou porque quer esclarecer que está retomando um elemento anterior no discurso.

${ }^{5}$ RIGAU (1986). 
10. Yo vi una película; él vio el partido. ${ }^{6}$

Geralmente, quando um elemento é introduzido no discurso é usado um SN (v. 11), e em novas menções pode ser usado o pronome (v. 11 ) se há necessidade de ênfase, se não houver essa necessidade, só o verbo é usado (v. 12,13) e é o suficiente para interpretar corretamente a oração:

11. Muchos años después, frente al pelotón de fusilamiento, el coronel Aureliano Buendía habia de recordar aquella tarde remota en que su padre lo llevó a conocer el bielo ${ }^{\text {? }}$.

12. Cuántas veces, Don Quijote, por esa misma llanura, en horas de desaliento asi te miro pasar...

13. Sean Connery apareció en la pantalla. Una vez más iba a representar al famoso agente.

A omissão do pronome na posição do sujeito acontece não somente na escrita mas também na fala. Esta característica dos pronomes tônicos sujeito diferencia a gramática do falante nativo de espanhol da gramática do falante brasileiro de português que, ao falar espanhol, vai ter a tendência de preencher sempre o lugar do sujeito.

Há casos em que o preenchimento da posição de sujeito com um pronome forte não é possível em espanhol:

\footnotetext{
${ }^{6}$ GROPPI (1997).

${ }^{7}$ GARCÍA MÁRQUEZ, Gabriel. Cien años de soledad. Buenos Aires. Sudamericana. 1970.

${ }^{8}$ FELIPE, León. Vencidos.
} 
14.

a. Não gosto desta saia. b. Ela é muito curta.

15.

a. No me gusta esta pollera. b. Es muy corta. c. ${ }^{*}$ Ella es muy corta.

Nestas orações é possível observar que o pronome português Ela retoma um antecedente não humano esta saia. $\mathrm{Na}$ oração do espanhol não aparece o pronome, só o verbo (Es) é usado. Neste caso, o problema não é que o emprego do pronome tônico sujeito produza estranheza no ouvido do nativo; trata-se de que o nativo não produz uma oração como 15 c.; como fica assinalado pelo asterisco, o resultado não é gramatical. Esses pronomes tônicos próprios para funcionar com sujeito supõem a retomada de antecedentes com o traço [animado], e só em casos de uso figurado, de personificações, podem apontar para referente que seja [-animado].

As formas tônicas que funcionam com preposição, ${ }^{9}$ no entanto, elas sim podem retomar elementos com o traço [animado]:

16. Cuando llegaron a la casa no encontraron a nadie en ella (= la casa).

Os pronomes tônicos aptos para funcionar como objeto de preposição também merecem comentários por oferecerem diferenças com formas semelhantes do português em suas possibilidades de emprego. É interessante observar estes exemplos:

${ }^{9}$ Ver a última coluna no quadro dos pronomes oferecido em 2. 
17.
a. Vi a Juan.
b. *Vi a él
c. *Vi él.
d. Lo vi a él.

O exemplo em 17b. mostra que a forma do pronome tônico objeto de preposição não pode ser usada como OD porque o resultado não é gramatical. A oração em c. indica que, se tirarmos a preposição, o resultado também não é gramatical. Vamos explicitar isso com clareza: não é uma estrutura que possa ser escutada e que a gramática normativa considere que não é uma forma correta.

Não é essa a situação. A oração 17c. está marcada com asterisco e isso significa que não há falante nativo que produza semelhante estrutura, seja um falante com alta escolaridade ou um falante com baixa escolaridade.Trata-se de uma regra categórica. Como b. indica, a forma tônica do pronome pessoal pode aparecer nessas estruturas se antecedida de preposição e se o pronome átono estiver presente.

Porém, não há exigência semelhante para as formas átonas: estas sim podem ocorrer para representar o objeto do verbo sem presença do pronome tônico:

18. Lo vi.

Esta estrutura é perfeitamente gramatical e a exigência para sua ocorrência é que resulte claro o antecedente do pronome, isto é, que esse pronome tenha um antecedente proeminente no discurso ou na situação. 


\section{Conclusão}

Perante a dimensão do tema, fizemos a escolha de tratar alguns pontos com referência aos que, segundo a experiência da docência nos diz, sempre permanecem dúvidas.

Nesta oportunida, de lembramos qual a característica que permite chamar uma palavra de pronome. A seguir, apresentamos as formas do sistema de pronomes pessoais do espanhol, classificando essas formas segundo traços fônicos (acento) e possibilidades de funções sintáticas.

Examinamos algumas características fundamentais das formas tônicas e foram apresentados exemplos que mostraram diferenças com a gramática do português.

Outros pontos que merecem consideração poderão ser abordados em próxima oportunidade. Assim, muito há para ser dito sobre o conjunto das formas átonas, por exemplo.

\section{Bibligrafia}

ALARCOS Llorach, Emilio. Estudios de gramática funcional del español, Madrid, Gredos. 1980.

ALARCOS Llorach, Emilio.Gramática de la Lengua Española, Madrid, Espasa Calpe. 1994

GROPPI, Mirta. Pronomes Pessoais no Português do Brasil e no Espanhol do Uruguai, Tese de Doutorado; ms. FFLCH USP. 1997.

FERNÁNDEZ-ORDÓÑEZ, Inés. Leísmo, laísmo y loísmo. Em: BOSQUE, I. y DEMONTE, V. Gramática Descriptiva de la Lengua Española. Madrid. Gredos. 1999. 
GROPPI, Mirta, Pronombres clíticos en el Español de Montevideo. Pragmalingüística, 5-6, pp 153-72.Universidad de Cádiz (Espanha). 1997-1998.

RIGAU, G. Some remarks on the nature of strong pronouns on null- subject languages. I. BORDELOIS, H. CONTRERAS y K.ZAGONA (eds) Generative Studies in Spanish Syntax. Foris: Dordrecht. 1986. 